\title{
Claims of Russian hacking in BDA elections
}

In a year which saw the British Dental Association (BDA) 'fire the starting gun on [its] biggest ever election', there have been worrying reports of possible outside interference in the election process for positions on the Chief Governing Body (CGB).

Early results indicate that $80 \%$ of the votes have gone to those candidates touting a move of BDA HQ from London to St Petersburg as part of a cost-saving exercise. One such candidate, Duncan McIliyov, a practice owner from Aberdeen, claims that the move could save over $£ 3,000$ a year in electricity costs. This may well be feasible because of an initiative from St Petersburg City Council in which they will provide free gas for the first three years to any associations choosing to relocate to Russia.

In mid-November, a large shipment of Caspian caviar and Belenkaya vodka was understood to have been delivered to 64 Wimpole Street. A spokesperson for the BDA said that this was a regular occurrence in preparation for the $\mathrm{BDA}$ annual Christmas bash which this year happened to have a Russian theme. This statement appeared to be backed up by a subsequent delivery of blinis, hammers, sickles and mini mince pies from Waitrose.

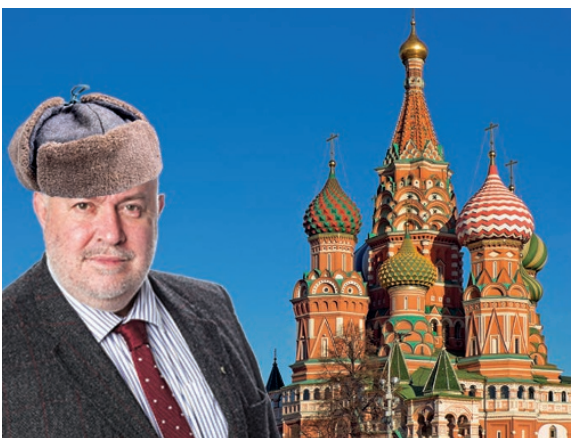

Mikail Armstrong

When questioned about the allegations of election hacking, BDA CEO Pyotr Wardovich (formerly Peter Ward) said, 'The BDA election process is as robust and healthy as ever, and we take very seriously any claims of interference in the process. We will investigate all real suggestions of hacking and collusion. On a completely separate matter, look out for some exciting news from us in the New Year about a new collaboration with Russia Today which could provide a significant solution for all dentists in relation to the perennial problem of waiting room television licensing.'

Mikail Armstrong, CEO of the BDA's CGB, was quick to dismiss the suggestion that the

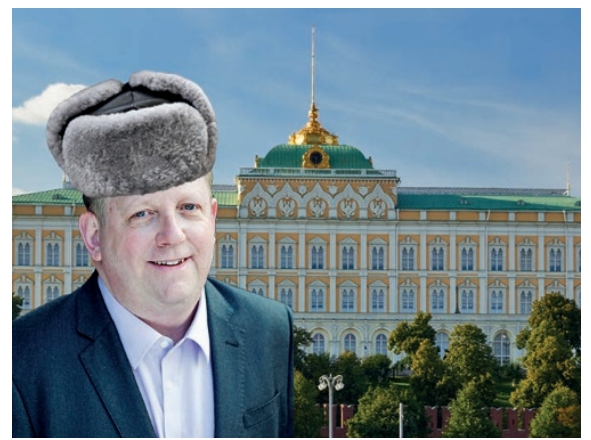

Pyotr Wardovich

BDA's central office might be moving east. He said 'If the HQ is moving anywhere it will be to the North of England.' Dr Armstrong, a well-known ballet lover, is himself documented as visiting Moscow over 15 times since January 2016 to attend the Bolshoi Theatre.

The final election results for all open CGB positions and other Council and Committee roles will be announced on 14 January 2018, coincidentally the day on which Russian Orthodox New Year will also be celebrated.

In other news, the BDA is considering putting in a joint bid with Broman Bramovich for Newcastle Utd FC in 2018, with a view to using the team to extend its reach in the North-East.

\section{Industry news}

\section{Product recall}

Conservative Restoratives Ltd has issued a product recall for the following product: Strong \& Stable Bond

The resin, though effective in initial testing and associated with the widely marketed 'Bonding means bonding' campaign, has been found to fail even under low level stresses encountered in the oral cavity. The product is therefore unsuitable for use on patients and could feasibly cause severe damage, particularly to children and vulnerable adults.

A new adhesive, DUP Prop Up, is currently under development. However, progress on the new product is slow despite significant investment of $£ 1$ billion.

If you have purchased any materials from the Strong \& Stable range since the launch in April 2017, please return to Conservative Restoratives Ltd by contacting Customer Services Manager Terry May at deadwomanwalking@CRLtd.com. A full refund will be issued (warning: a protracted negotiation period may be necessary before any refund is agreed).

\section{Profit warning}

LeftLab Loupes plc, well-known makers of both 'Union Loupes', claimed to make life easier for all dentists' eyes, and the trendsetting 'Momentum Loupes', popular with younger dentists, has issued a profit-warning ahead of its shareholder meeting in early 2018. It seems as if their policy of loupes 'for the many and not the few' and the nationalisation of loupe wearing for all people, not just dentists, is not producing the expected revenue.
Critics of LeftLab Loupes plc accounting policies indicate that the problem with the company is the lack of mathematical ability amongst its directors. They say the sums just don't add up. Jerry Corbyn, the popular CEO of LeftLab, disagrees and is asking shareholders to just hold tough for another 20 years, when it is reported that robotic flying pigs currently undergoing development in Japan may be entering the mass production phase. These pigs will most certainly require ocular assistance as flying requires sharp eyesight and the usual solution of eating carrots has shown to be completely ineffective for robots. Supplying loupes to the Japanese pig manufacturers is where Corbyn feels LeftLab will come into their own. However, only time will tell if LeftLab Loupes shareholders are willing to go the distance with him. 